Article

\title{
Methane Desorption Characteristics of Coal at Different Water Injection Pressures Based on Pore Size Distribution Law
}

\author{
Dong Zhao ${ }^{1,2,3, *(\mathbb{D})}$, Tao Gao ${ }^{1,2,3}$, Yulin $\mathrm{Ma}^{4}$ and Zengchao Feng ${ }^{2, *}$ \\ 1 Department of Safety Science and Engineering, Taiyuan University of Technology, Taiyuan 030024, China; \\ gaotao0412@link.tyut.edu.cn \\ 2 Key Laboratory of In Situ Property-Improving Mining of Ministry of Education, Taiyuan University of \\ Technology, Taiyuan 030024, China \\ 3 Graduate Student Education and Innovation Center in Coal Mine safety of Shanxi Province, \\ Taiyuan 030024, China \\ 4 School of Mechanics \& Engineering, Liaoning Technical University, Fuxing 123000, China; \\ hxwyaoyao@163.com \\ * $\quad$ Correspondence: zhaodong@tyut.edu.cn (D.Z.); zc-feng@163.com (Z.F.)
}

Received: 12 August 2018; Accepted: 4 September 2018; Published: 5 September 2018

check for updates

\begin{abstract}
Methane desorption characteristics of coal under definite water pressure comprises a complex two-phase flow process. A series of mercury intrusion porosimetry (MIP) and desorption experiments at different water injection pressures are reported in this study. Three lumpy coal samples were used in desorption experiments at three different water injection pressures and at natural desorption for comparison. Samples comprising two ranks of coal were used for MIP measurements including the distribution of porosity and pore sizes. The results of this study enable the establishment of a new model that encompasses a critical theoretical pore size that is most effective for water injection into coalbeds and that can be related to water injection pressure, the length of residual water, and gas adsorption capacity. Data show that the use of different water injection pressures leads to different gas desorption capacities as well as variable time effects and degree of gas desorption. Critical pore size is therefore proposed as a new parameter that can be employed to describe high pressure water effects in the context of gas desorption and can be calculated using pore size and the volume distribution law, as well as via the moisture ratio that remains after experiments and the permanent desorption percentage.
\end{abstract}

Keywords: two-phase flow model; critical pore size; desorption; lumpy coal samples; pressured water

\section{Introduction}

Coalbed methane (CBM) is a significant natural energy resource that is increasingly playing a key role in the development of clean new energy in China. As the production of natural gas from coal and CBM from shallow hydrocarbon deposits is now relatively widespread, it is increasingly important to investigate the simultaneous adsorption and desorption of coalbed gases and water to enable more efficient exploitation [1-5]. Methane desorption from coal at various conditions is affected by numerous factors-including gas content from underground boreholes, coalbed permeability, initial gas desorption properties, and coal strength—all variables that can be measured in the laboratory as well as in situ at the coal field [6-9].

Seam permeability during gas discharge is complex and can be influenced by the coupled processes of gas migration and coalbed deformation. The dual mechanisms of coupled flow and deformation on CBM recovery have attracted a great deal of attention and has led to significant 
achievements [10]. A range of studies have assessed how high-pressure water injection into a coalbed will influence the desorption capacity of $\mathrm{CH}_{4}$ because of residual moisture $[5,11-13]$. This process can also improve coalbed permeability although gas output is also influenced by high pressures as moisture content increases [14,15]. Additional technologies, including carbon dioxide enhanced coalbed methane (CO2-ECBM) and coalbed heating, can also be utilized for CBM exploitation [16,17]; all these methods improve gas production and break original adsorption and desorption equilibrium states to create very large discrepancies between experimental processes and engineering practice [18].

To describe how desorption volumes gradually decrease with the amount of injected water, it is necessary to understand both pore size and the volume distribution law within this field. This is because pores and fissures are good places for gas and water to co-exist. Coal bodies can therefore both swell and shrink during adsorption and desorption due to porous features [19-22]. Different pore structures and fractal laws within coal have different adsorption and desorption capacities as macro pores have significant impacts on gas flow in both bituminous and subbituminous coals. This means that the higher the macro-porosity, the better the gas flow capability [23-25].

For the pore size distribution law about porous media, it is widely used in all industry area such as agroindustrial waste, sludge, as well as coal. Some meso testing methods like X-ray computed tomography, mercury intrusion porosimetry(MIP), petrographic analysis, ultrasonic, nuclear magnetic resonance, and scanning electron microscopy have been used [26-28]. These technologies are all valuable to analysis or evaluate the pore size distribution properties of porous materials.

In two-phase coalbed flow, moisture content decreases as pore specific volume increases as measured using nuclear magnetic resonance cytophotometry [29,30]. Gas desorption and transport within the coal matrix has also been illustrated to be a non-linear phenomenon, and therefore a modified version of Fick's diffusion model called the density model has been proposed and some experiments have been performed [17,31,32]. A complex two-phase flow process within coal is induced by porosity and pore size distribution once water is injected into $\mathrm{CH}_{4}$ bearing coalbeds $[33,34]$. From the above contents, there is a research gap between gas desorption or production capacity and pore size distribution that needs to be addressed.

Two ranks of coal samples were used in this study in a series of desorption experiments at different water injection pressures combined with mercury intrusion porosimetry (MIP) measurements to study the relationship between desorption law and pore size distributions. A critical pore size has been established combining two-phase flow in coal as a new parameter to describe high pressure water effects as components of gas desorption.

The aim of this study is to predict gas and water flows within coalbeds as these variables are dependent on adsorbed gas and high-pressure water. We also reveal the underlying distribution laws controlling both two-phase flow and seepage.

\section{Theoretical Study}

The tube used in this study was an imaginary tube and made from coal material with one side open and the other closed with measurable length and inner diameter parameters. The gas $\mathrm{CH}_{4}$ was then passed into this tube under pressure while water was injected from the open side. Equilibrium was reached in this case depending on water pressure, length, and the inner diameter of the tube. The relationship between water injection and gas pressures conforms to Equation $(1)[35,36]$ as

$$
p=p_{1}+p_{2}
$$

Gas pressure within the tube will be greater than the capillary force when water flow is reversed as pressure is unloaded. Thus, if gas pressure in the tube is equal to capillary force, the relationship between these two variables will conform to Equation (2) as

$$
p_{1}{ }^{\prime}=p_{2}{ }^{\prime}
$$


The interactions between gas and water are summarized in Figure 1.

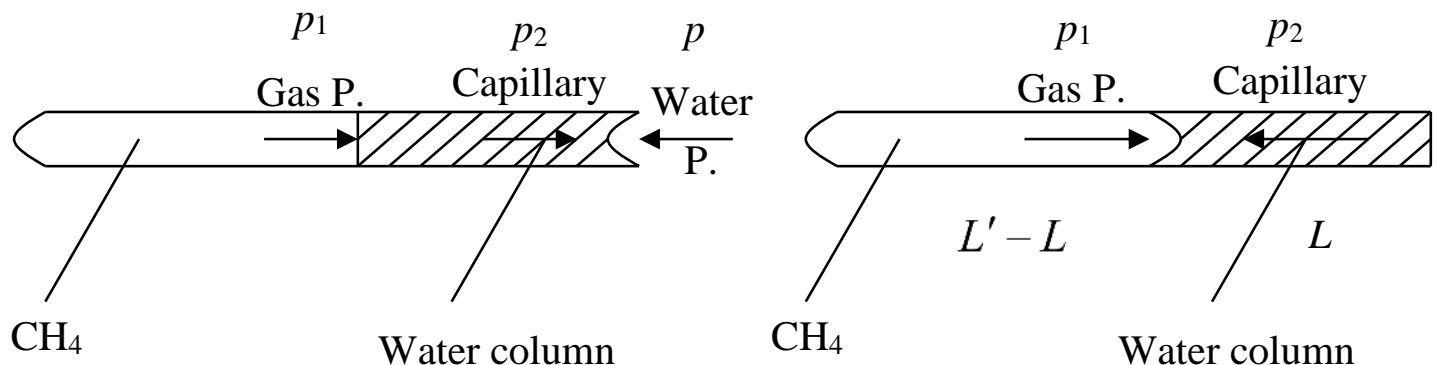

(a)

(b)

Figure 1. Schematic to show the coupling between liquid and gas. (a) Water injection process; (b) Water pressure unloaded process.

Combing Knudsen number which representing gas diffusion type, Knudsen number $(\mathrm{Kn})$ is equal to molecular average free path divide by average diameter of pore [37]. For gas diffusion in pores, if $\mathrm{Kn}$ is less than 0.1, it obeys Knudsen diffusion; if $\mathrm{Kn}$ is more than 10, it obeys Fick diffusion; if $\mathrm{Kn}$ is between the above two numbers, it obeys intermediate state diffusion.

Water injection pressure remains constant throughout this process (Figure 1) as the initial gas pressure in the tube is less than this corresponding variable. A water column is formed within the tube as this process continues, and capillary force increases as this structure expands in concert with gas pressure as volume decreases. Assuming no exchange of matter and that temperature remains constant, the ideal gas state Equation (3) should be formed as

$$
\begin{gathered}
p V=\text { constant } \\
p_{0} V_{0}=p_{1} V_{1}
\end{gathered}
$$

The volume decrease rate in this case is equal to the pressure increase rate while capillary tension induced by water column depends on the length of the water column and is reversed versus the diameter of the tube. These variables conform to Equation (5) as

$$
p_{2}=k \frac{L}{A}
$$

As the volume of the water in the tube is equal to length multiply by cross-sectional area, it therefore follows that

$$
V_{0}=L^{\prime} A
$$

Thus, building on Equations (1) and (4) to (6), it therefore follows that

$$
p=\frac{p_{0} L^{\prime}}{L^{\prime}-L}+k \frac{L}{A}
$$

Equation (7) denotes the relationship between the water injection pressure, length of the water column, and the cross-sectional area of the tube under initial gas pressure conditions such that lengths remain constant.

As shown in Figure 1b, transient gas pressure within the tube is greater than capillary tension once water pressure is unloaded. The water column was then displaced with gas to reverse the water injection side, while at the same time, column length was decreased as both gas movement and pressure increase with closed volume. Capillary tension always existed before the water column 
moved out of the tube; thus, assuming gas pressure within the tube is equal to the capillary tension of water, Equation (2) could be modified as

$$
p_{1}^{\prime}=\frac{p_{0} V_{0}}{V_{1}^{\prime}}=k \frac{L_{2}^{\prime}}{A}=p_{2}^{\prime}
$$

and

$$
\frac{p_{0} V_{0}}{V_{1}^{\prime}}=p_{0} \frac{L^{\prime} A}{L_{2}^{\prime} A}=\frac{p_{0} L^{\prime}}{L_{2}^{\prime}}
$$

Equations (8) and (9) can therefore be combined as

$$
p_{0}=\frac{k\left(L_{2}^{\prime}\right)^{2}}{A L^{\prime}}
$$

Substituting Equation (10) into Equation (7), it therefore follows that

$$
p=\frac{k}{A}\left[\frac{\left(L_{2}^{\prime}\right)^{2}}{L^{\prime}-L}+L\right]
$$

Equation (11) represents a new model that expresses critical pore size $D$ [D equal to $\left(\frac{4 A}{\pi}\right)^{1 / 2} * 10^{-3}$ ] in cases where water is injected into coalbeds.

Figure 1 shows the relationship between water column movement and the length of water column in each tube; this latter structure will disappear during experiments are determined by water injection pressure via gas desorption. Indeed, capillary tension is also affected by inner tube diameter; data show that critical pore size for water injection into coalbeds depends on water injection pressure. Whether or not capillary tension is greater than gas pressure depends on the nature of the water column and increases in capillary tension. Water in coals moves out of pores and fissures once water pressure is unloaded and this depends on column length and gas pressure. In terms of equilibrium state, water is always present in pores and adsorbent gases cannot be desorbed through this way at constant atmospheric pressures and temperatures. This phenomenon results in a gas desorption capacity that decreases as water pressure increases even though some adsorbed gas remains in coal. A higher water injection pressure leads to a similar distribution of pores and fissures in coal; in other words, the greater the length of the residual water column in a coalbed, the less gas is desorbed.

\section{Methodology}

\subsection{Samples}

The samples used in this study taken from No. 3 Coalbed within the Tunliu Mine in Lu'an District and from the No. 9 Coalbed in Kaiyuan Mine within Yangquan District. The first set of samples comprise lean coal while the latter is anthracite; in each case, three cylindrical lumpy coal pieces $100 \mathrm{~mm}$ in diameter and $150 \mathrm{~mm}$ in height were machined using an abrasive wire sawing machine (DL5640, Delong CNC Equipment Co. 1td., Taizhou, Jiangsu Province, China) (samples are illustrated in Figure 2 and the abrasive wire sawing machine is illustrated in Figure S1 of Supplementary). As these lumpy coals contain both raw pores and fissures, they are suitable for in situ simulations; samples were numbered as lean coals 1-1 and 1-2 for analysis at different equilibrium gas adsorption pressures. Similarly, the anthracites were numbered as 2-1; prior to each experiment, samples were placed in a dryer for between 12 and $16 \mathrm{~h}$ at $106^{\circ} \mathrm{C}$ to completely evaporate all moisture. 

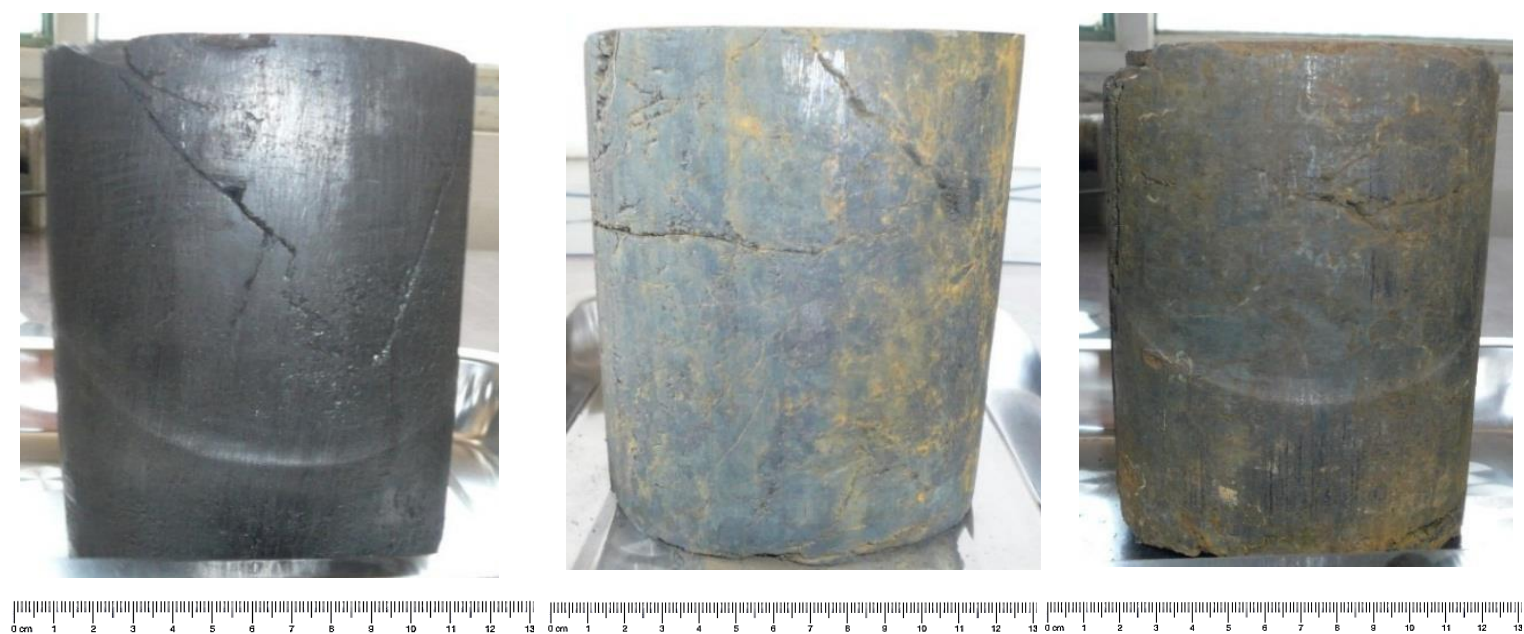

Figure 2. The lumpy coal experimental samples used in this study (from left to right are 1-1, 1-2, and 2-1, respectively).

MIP was used in this study to illustrate pore sizes and the structural distribution of different coal ranks at the microscale. Once the distribution of pore sizes and structural characteristics were assessed using MIP, they were compared with adsorption and desorption experiments on lumpy coal. These samples were then machined into small cubes that weighed between 1.0 and $1.5 \mathrm{~g}$ in each case. The coal sample from Tunliu Mine was marked as Sample 1 while its counterpart from Kaiyuan Mine was marked as Sample 2. Proximate and elemental analyses, vitrinite reflectance, and the definition of coal rank were performed for all samples (Table 1).

Table 1. Results of proximate analyses performed on different coal sample ranks.

\begin{tabular}{cccccccc}
\hline \multirow{2}{*}{ Sample } & \multicolumn{4}{c}{ Proximate Analysis (\%) } & \multicolumn{3}{c}{$\mathbf{R}_{\mathbf{0} \max }(\mathbf{\%})$, Coal Rank and Type } \\
\cline { 2 - 8 } & Ash & VM & FC & $\mathbf{S}$ & $\mathbf{R}_{\mathbf{0} \max }$ & Definition of Coal Rank & Coal Type \\
\hline Luan (1) & 8.46 & 17.10 & 82.91 & 0.51 & 1.74 & High-grade bitumite & Lean coal \\
Yangquan (2) & 10.12 & 9.42 & 89.56 & 0.49 & 2.53 & Low-grade anthracite & Anthracite \\
\hline
\end{tabular}

Ash and total sulfur (S) were calculated on a dry basis. Volatile matter (VM) and fixed carbon (FC) were calculated on a dried, ash-free basis. $R_{0 \text { max }}$ is maximum reflectance of vitrinite.

\subsection{Experimental Apparatus}

We developed an experimental system to study the adsorption and desorption characteristics of coal mass samples and to carry out simulated water injection CBM experiments. This set-up includes a stainless-steel container that can withstand pressures up to $20 \mathrm{MPa}$ and that has top and bottom openings with flexible seals. The upper part is used to inject and produce gas while the bottom part is used to inject water; a columnar coal sample is then placed inside the container which is surrounded by a temperature-controlled air bath. Water injection and gas production components within this system are similar to an in situ gas production project because of the presence of water injection and gas production wells. These coal mass samples therefore simulate an ideal coal bed following hydro-fracture. Although gas usually desorbs rapidly, once water has been injected, this process slows down and becomes less efficient. A series of experiments were therefore performed at different water pressures to determine desorption behavior (Figure 3). We have previously reported detailed information about this apparatus [13]. 


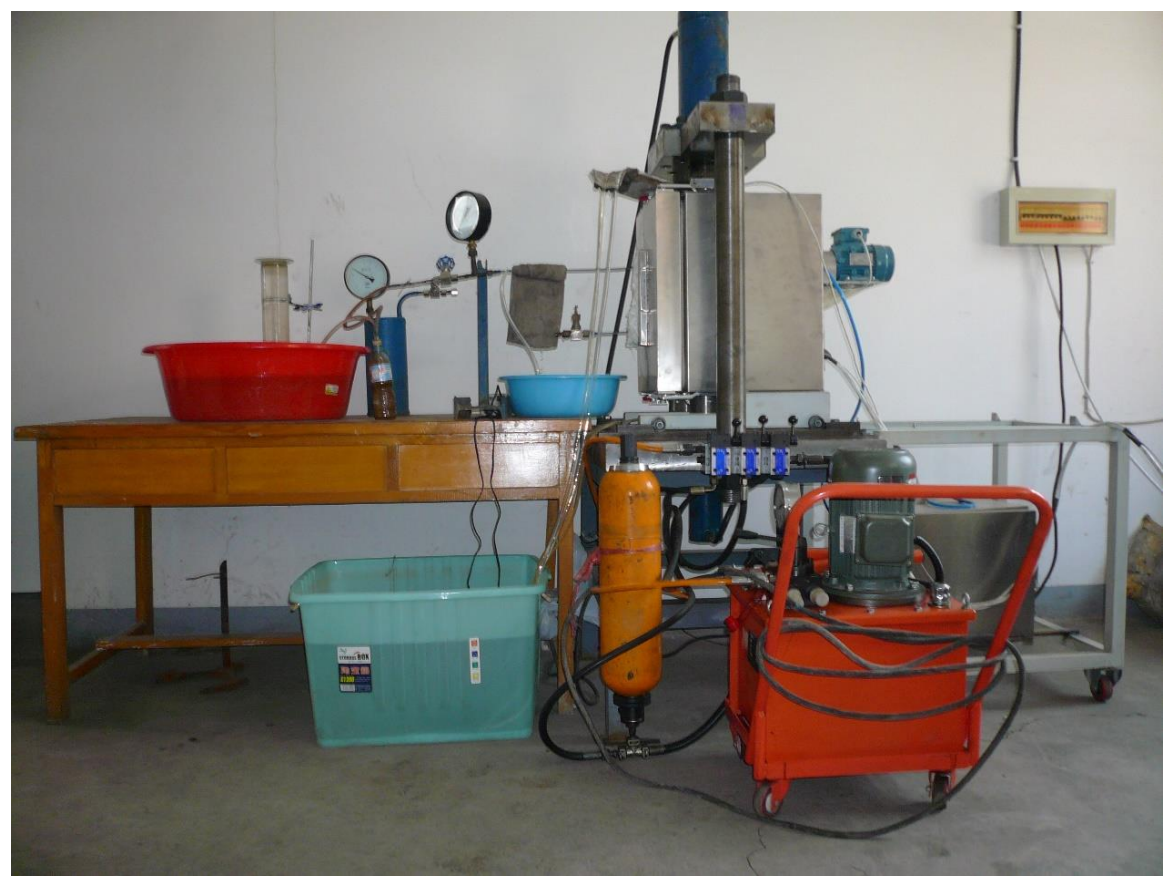

Figure 3. Picture of the experimental apparatus used in this study.

\subsection{MIP Procedures}

MIP measurements were made using a porosity instruments (Model 9310, Micromeritics Instruments Co. Ltd., Norcross, GA, USA) at working pressure between 0.0035 and 206.843 MPa, a resolution ratio of $0.1 \mathrm{~mm}^{3}$, a sample tube volume of $5.1669 \mathrm{~cm}^{3}$, and a minimum 6 nm pore size. The weight of Sample 1 was $1.1207 \mathrm{~g}$ while the weight of Sample 2 was $1.1430 \mathrm{~g}$. Samples were placed in a dryer for $12 \mathrm{~h}$ at $90^{\circ} \mathrm{C}$ and vacuumed prior to all experiments.

For an error analysis on MIP measurements, there are two hypotheses based on Washburn's equation: one is all of the pores are cylinder, and the other is all of the pores could be connected to the surface of sample [38]. Then, pore form, contact angle, and surface tension are all caused theoretical errors. Beyond this, system factors such as interspace, compressibility of mercury and sample are all caused results errors. Interspace is the space between the sample and tube, it is gradually increased with the mercury pressure increased. There is a compressibility factor about mercury and sample, and it is variated with pressure changed. So, based on these potential errors in MIP measurements, we can reduce the errors to the minimum in rigid operating instruction.

Pore size was calculated using mercury intrusion pressure and accumulated volume in nm-scale units [39]. Pore volume was then equated to accumulated mercury volume, in units of $\mathrm{mL} / \mathrm{g}$, while specific surface area was calculated from pore size and volume, assuming these structures at spherical. The relationship between pore size and mercury intrusion volume conforms to Equation (12) as

$$
r=-\frac{2 \sigma \cos \alpha}{p}
$$

For mercury, $\alpha$ equal to $142^{\circ}$ for the two samples.

\subsection{Experimental Procedures}

Samples were placed in an adsorption-water injection-desorption apparatus at $25^{\circ} \mathrm{C}$ equivalents to simulate coal reservoir temperature. The free volume of coal in containers was measured prior to experiments while the procedures used in this study can be divided into three steps.

The first step of this process comprises adsorption, checking the airtight nature of the experimental device using high-pressure helium for more than $48 \mathrm{~h}$. The valve was then opened to connect gas and 
sample containers so that coal sample could adsorb gas, a process which lasted between three days and seven days until gas pressure was constant. The rated adsorption pressure and change during the adsorption process was recorded using a digital gauge.

The second step of this process comprises high-pressure water injection, connecting M1 to M3 following coal sample adsorption to an equilibrium state. Water pressure was controlled in this case using a pump in M1 divided into four different pressures, including equal gas pressure (One-time), 3 times gas pressure ( 3 times), and 9 times gas pressure (9 times). In addition, natural desorption without water injection after adsorption is also necessary; water was passed through the entire coal sample during this process which maintained this state for $24 \mathrm{~h}$ within the coal sample container. This process simulates moisture injection within an in situ coal seam.

The third step of this process is desorption, separated into two distinct phases. In the first of these, M4 is connected to M3 for desorption under atmospheric pressure. This process lasts $48 \mathrm{~h}$ in each case; the amount of gas was measured in each case in real time during the experiment and desorption equilibrium was considered attained once desorption velocity fell to less than $10 \mathrm{~mL} / \mathrm{h}$. The temperature of desorption was maintained at $25^{\circ} \mathrm{C}$. The weight of each coal sample was then measured and its moisture ratio following water injection and desorption was calculated subsequent to the desorption process.

\section{Results}

\subsection{MIP Experimental Results}

The accumulated volume of mercury intrusion, ejection rate, and the distribution of pore sizes in the two coal samples assessed in this study are presented in Figure 4a. Data show that at the same mercury intrusion pressure, the porosity of coal Sample 1 is about twice that of Sample 2 at each stage although the intrusion and ejection of mercury are not completely reversible. The distribution law that controls accumulated pore size in these two coal samples can be seen in Figure 4b, while the law that controls the accumulation of specific surface area versus pore size in the two samples is outlined in Figure 4c. Data show that the porosity, pore volume, and specific surface area of coal Sample 1 are again about twice those of Sample 2. The relationships between pore volumes at different sizes are summarized in Table 2.

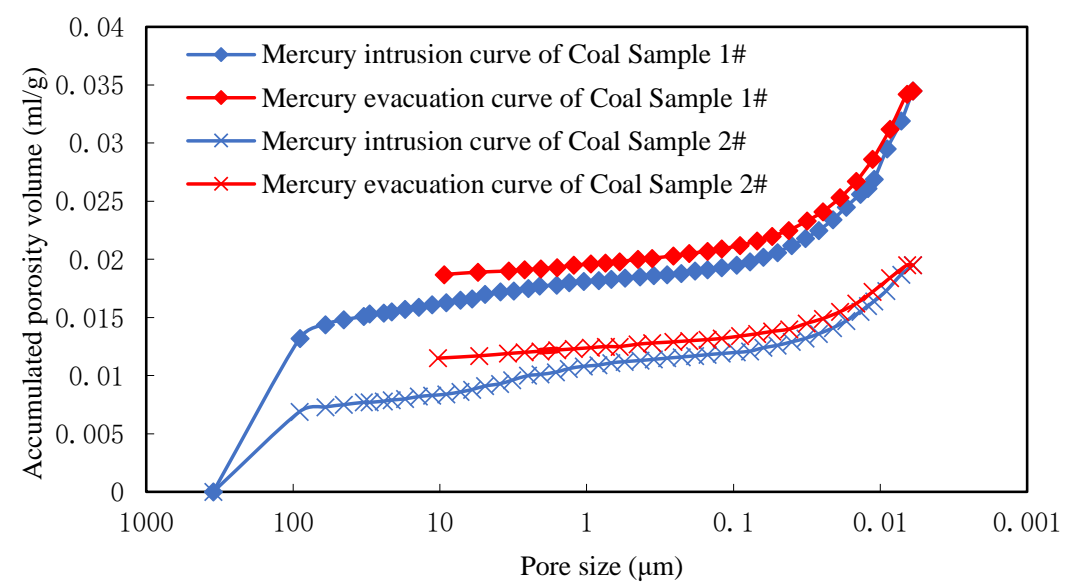

(a)

Figure 4. Cont. 


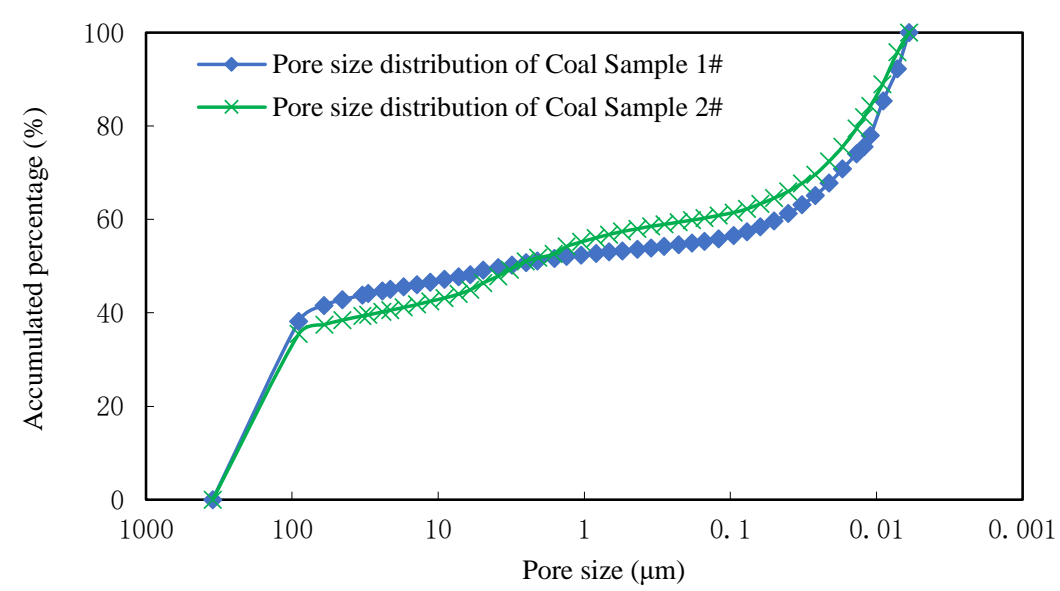

(b)

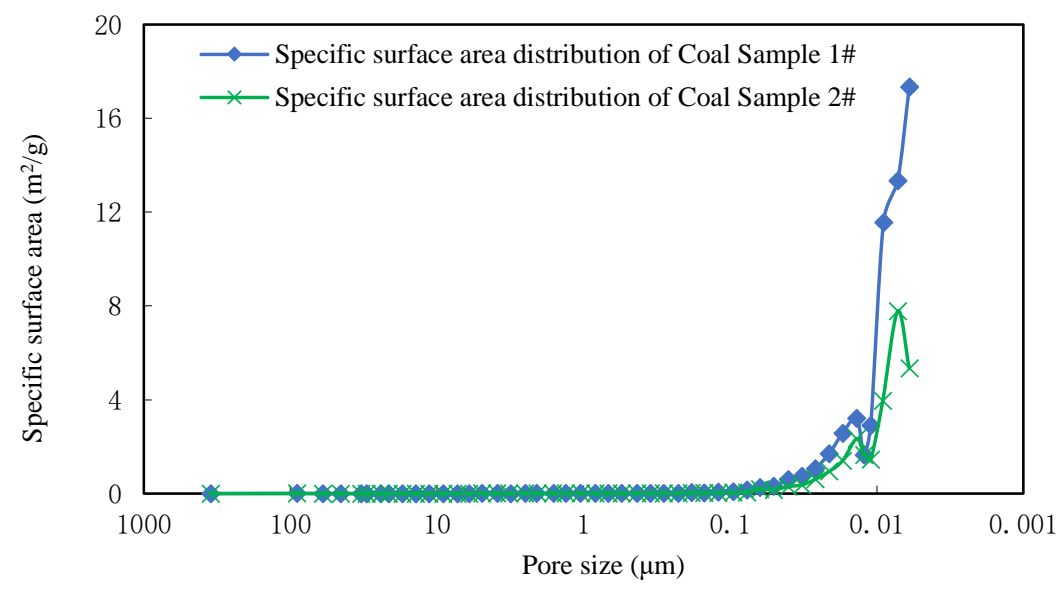

(c)

Figure 4. Testing results of MIP experiments: (a) Curves to summarize mercury intrusion and evacuation from the two coal samples assessed in this research; (b) pore size distribution curves for the two coal samples assessed in this research; (c) specific surface area distribution curves for the two coal samples assessed in this research.

Table 2. Pore volumes and specific surface areas of coal Samples 1 and 2 across different size ranges

\begin{tabular}{ccccc}
\hline \multirow{2}{*}{$\begin{array}{c}\text { Pore Size } \\
\text { Distribution mm }\end{array}$} & \multicolumn{2}{c}{ Coal Sample 1 } & \multicolumn{2}{c}{ Coal Sample 2 } \\
\cline { 2 - 5 } & Pore Volumes $\mathbf{~ m L / g}$ & Specific Area $\mathbf{~ m}^{\mathbf{2}} / \mathbf{g}$ & Pore Volumes $\mathbf{~ m L / g}$ & Specific Area $\mathbf{~ m}^{\mathbf{2}} / \mathbf{g}$ \\
\hline$>10 \mu \mathrm{m}$ & 0.0161 & 0.00097 & 0.0083 & 0.00053 \\
$1 \mu \mathrm{m} \sim 10 \mu \mathrm{m}$ & 0.0020 & 0.00286 & 0.0025 & 0.00409 \\
$0.1 \mu \mathrm{m} \sim 1 \mu \mathrm{m}$ & 0.0012 & 0.02068 & 0.0011 & 0.01578 \\
$10 \mathrm{~nm} \sim 100 \mathrm{~nm}$ & 0.0076 & 1.52528 & 0.0045 & 0.95018 \\
$6 \mathrm{~nm} \sim 9 \mathrm{~nm}$ & 0.0076 & 4.22222 & 0.0031 & 1.70672 \\
Total & 0.0345 & 5.77201 & 0.0195 & 2.67730 \\
\hline
\end{tabular}

\subsection{Water Injection Induced Desorption Experimental Results}

Desorption percentages as a function of time for coal Samples 1-1, 1-2, and 2-1 at different water injection pressures are presented in Figure 5. This percentage denotes a physical quantity to illustrate desorption capacity; thus, transient and permanent desorption percentage can be calculated using Equations (13) and (14) as

$$
\eta_{T}=V_{T} / V_{A} .
$$


and

$$
\eta_{P}=V_{P} / V_{A}
$$

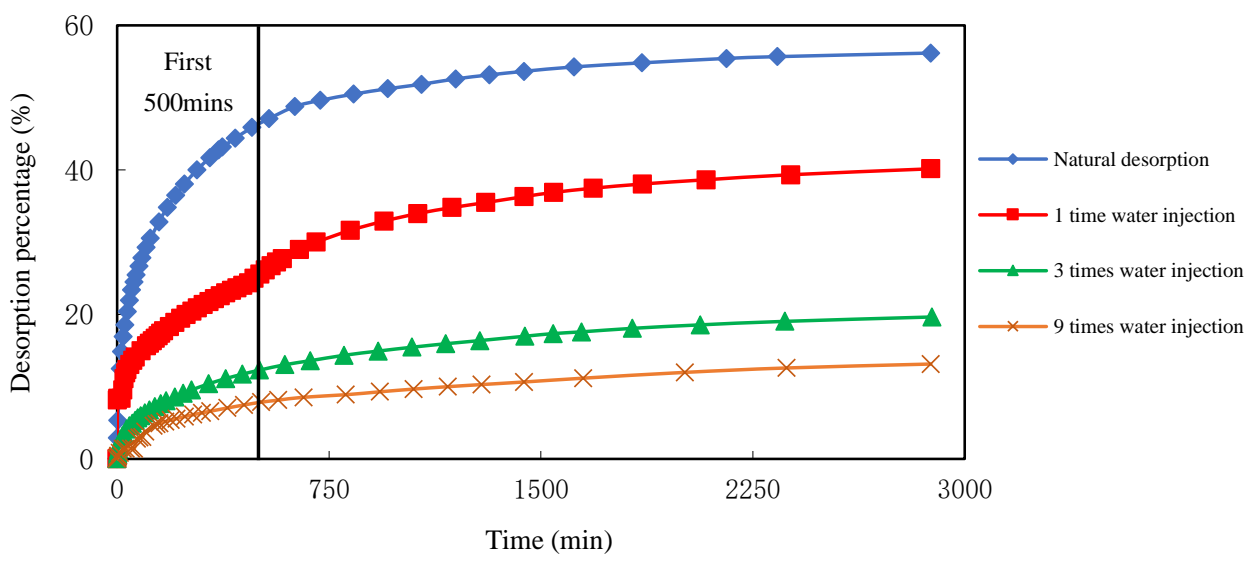

(a)

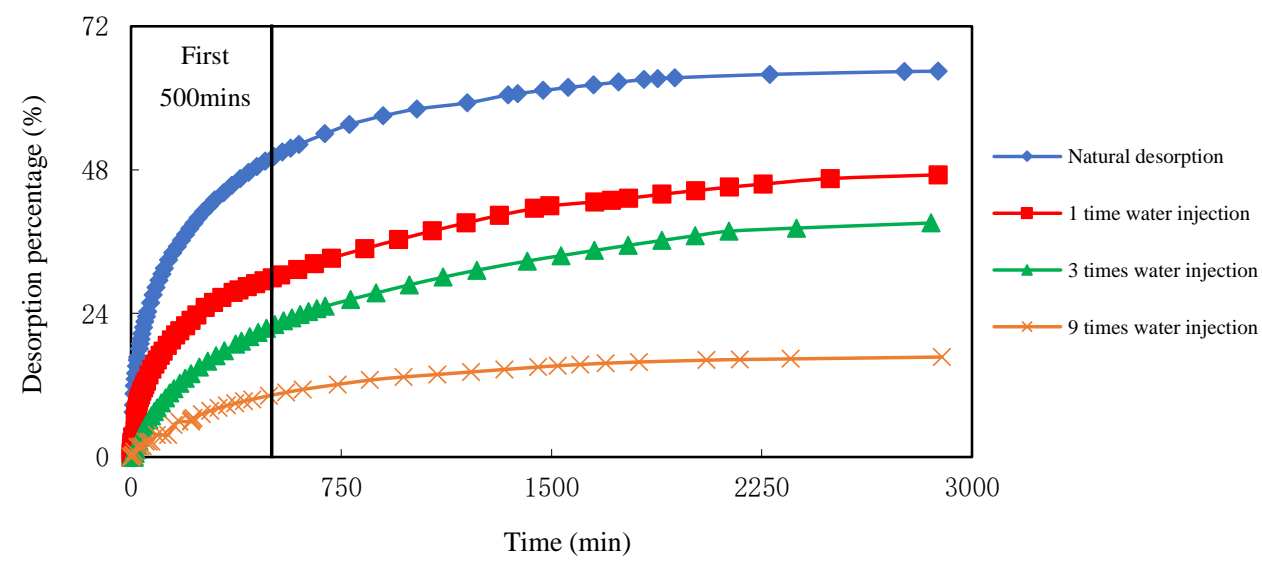

(b)

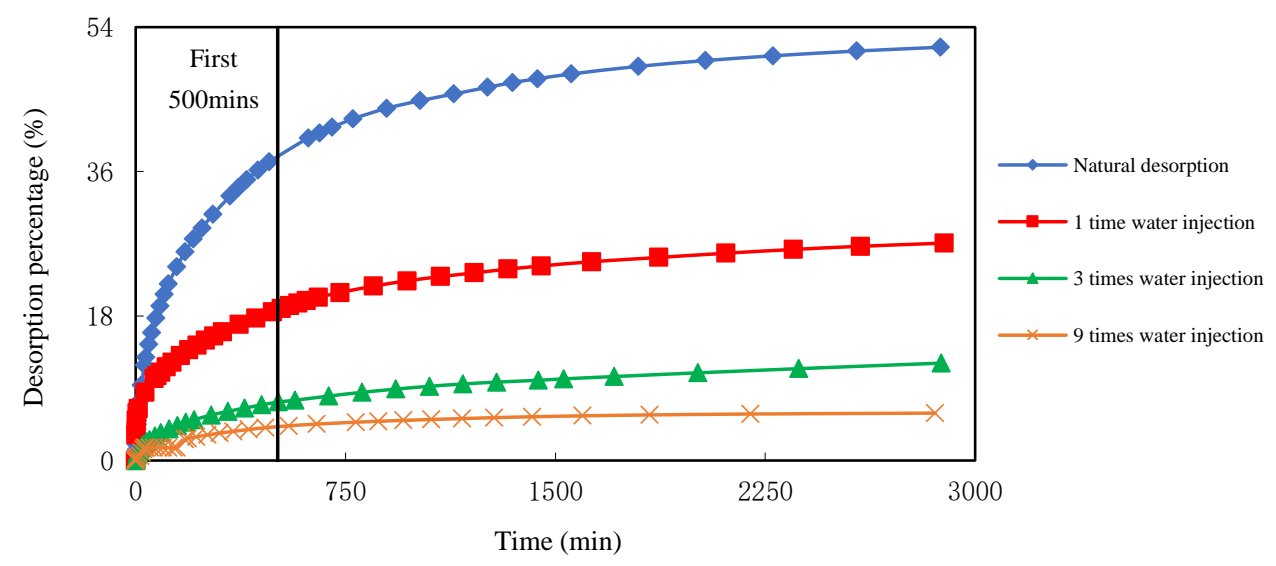

(c)

Figure 5. Desorption percentage as a function of time for coal samples at different water injection pressures. (a) Coal Sample 1-1; (b) Coal Sample 1-2; (c) Coal Sample 2-1. 
The data presented in Figure 5 show that both transient and permanent desorption percentages decrease as water injection pressure increases. Desorption percentage is therefore a valid proxy that can be used to objectively describe these processes. Results show that after the first $500 \mathrm{~min}$ of natural desorption, transient desorption percentage remains at $\sim 80 \%$ of the permanent level, while after one period of water injection pressure, transient values remain at $\sim 70 \%$ of the permanent level. Similarly, at three times this pressure level, transient values fall between $60 \%$ and $63 \%$ of their permanent levels while at nine times pressure, transient values are between about $50 \%$ and $55 \%$ of permanent levels. Larger declines are seen in natural cases, at one and three times desorption while smaller declines are seen between three and nine times desorption levels

\subsection{Moisture Ratio Subsequent to Desorption Experiments}

Water sorption behavior is presented as moisture ratio. In natural state, coal could adsorb water both in surface and interpore. The cohesion both coal and water are in basis of hygroscopicity. It is different from pore size distribution law of coal.

Values of permanent desorption percentage as a function of water injection pressure for the three coal samples studied in this research are presented in Figure 6. The moisture ratio of each sample subsequent to desorption is a specific value that expresses the relationship between water mass in pure and lumpy coals. As molecules of water can penetrate into smaller pores and fissures as injection pressure increases, the moisture ratio therefore increases as a function of water pressure. Results for moisture ratios subsequent to each desorption stage are presented in Table 3; these data correspond with permanent desorption percentages.

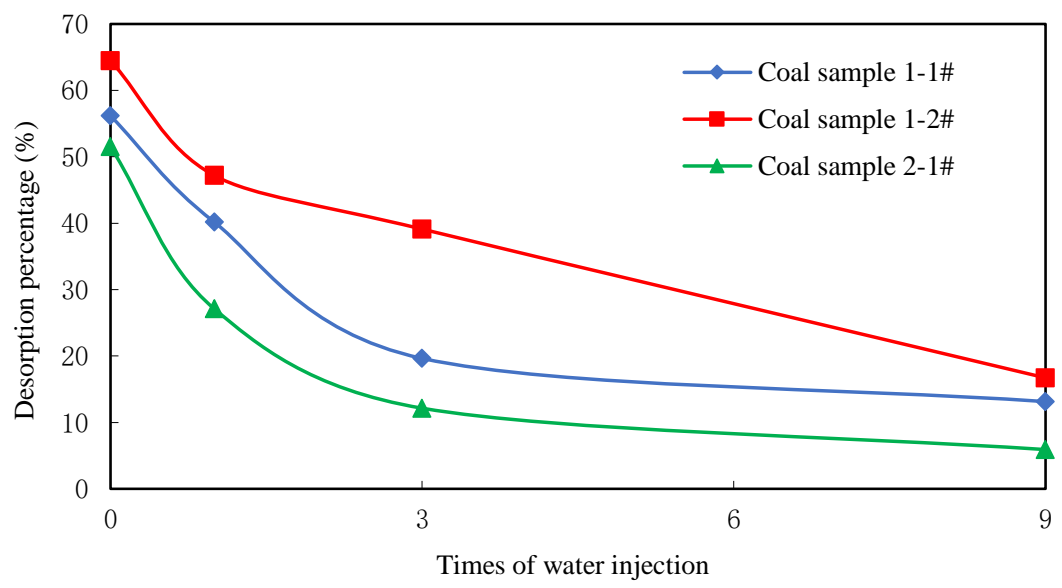

Figure 6. Permanent desorption percentage as a function of water injection pressure for the three coal samples studied in this paper ( 0 of $x$-axis represents natural desorption stage without water injection).

Table 3. Desorption and moisture values after experiments

\begin{tabular}{ccccc}
\hline \hline Condition of Desorption & Coal Sample No. & $\mathbf{1 - 1}$ & $\mathbf{1 - 2}$ & $\mathbf{2 - 1}$ \\
\hline Natural adsorb water & Moisture \% & 2.70 & 2.70 & 1.30 \\
\hline \multirow{2}{*}{ Natural desorption } & Desorption \% & 56.17 & 64.48 & 51.50 \\
& Moisture \% & $/$ & $/$ & $/$ \\
\hline One-time water pressure & Desorption \% & 40.15 & 47.17 & 25.30 \\
for desorption & Moisture \% & 2.75 & 2.74 & 1.51 \\
\hline Three-times water & Desorption \% & 19.64 & 39.11 & 12.14 \\
pressure for desorption & Moisture \% & 2.90 & 2.83 & 1.57 \\
\hline Nine-times water pressure & Desorption \% & 13.13 & 16.71 & 5.909 \\
for desorption & Moisture \% & 2.94 & 2.91 & 1.70 \\
\hline
\end{tabular}




\section{Discussion}

\subsection{Critical Pore Size Calculations}

Critical pore size refers to the minimum pore size into which water can penetrate at constant pressure and will depend on both gas and water pressure. Moisture ratios, permanent desorption percentages at different water injection pressures, and MIP results all reveal that critical pore sizes at different stages can be calculated using Equation (1). The contact angles for these two coal samples were then measured and results were presented in Figure 7; these data show that the contact angle of coal Sample 1 is $150^{\circ}$ while that of Sample 2 is $120^{\circ}$. As parameter $p$ in Equation (1) is water injection pressure, result subsequent to critical pore size calculations are presented in Table 4 . The minimum pore sizes of coal induced by water fall between 12 and $200 \mathrm{~nm}$ in the absence of gas pressure.

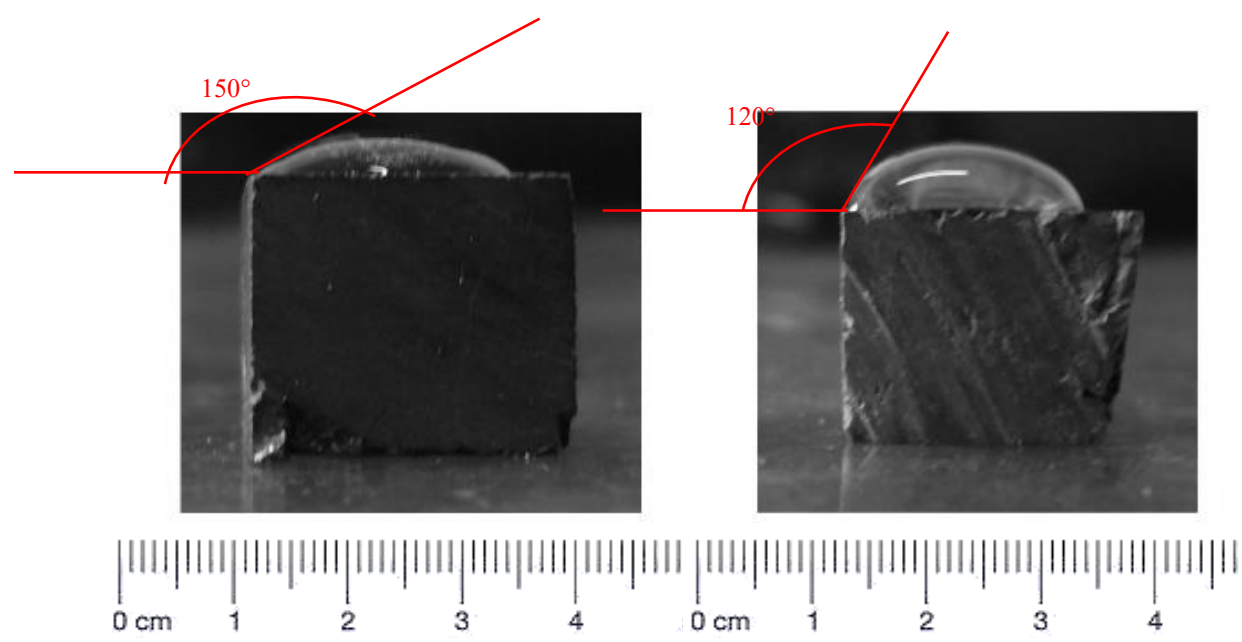

(a)

(b)

Figure 7. Contact angles for the two coal samples induced by water. (a) Coal Sample 1; (b) Coal Sample 2

Table 4. Critical pore sizes induced by water

\begin{tabular}{cccc}
\hline \multirow{2}{*}{ Desorption Condition } & \multicolumn{3}{c}{ Pore Size-Scale/nm } \\
\cline { 2 - 4 } & $\mathbf{1 - 1}$ & $\mathbf{1 - 2}$ & $\mathbf{2 - 1}$ \\
\hline Natural adsorb water & 1017 & 1017 & 1185 \\
One-time water pressure for desorption & 156.5 & 113.0 & 182.3 \\
Three-times water pressure for desorption & 52.18 & 37.68 & 60.75 \\
Nine-times water pressure for desorption & 17.39 & 12.56 & 20.25 \\
\hline
\end{tabular}

Analysis based on MIP reveal the relationship between pore size and accumulated volumes (Table 5) that can be compared with those in Table 4. Data show that accumulated pore volumes gradually increased as pore sizes decrease, while the theoretical moisture ratios of coal increase with water injection pressure.

Moisture ratios and accumulated pore volumes were calculated on the basis of water density equal to $1 \mathrm{~g} / \mathrm{mL}$. This means that based on the moisture ratio in a natural water adsorption state as well as pore size after a sample was vacuumed, the whole volumes of surface fissures can be calculated using Equation (15) as

$$
V_{1}=\frac{M}{100 \rho}-V_{0}
$$


Table 5. Pore sizes and accumulated pore volumes

\begin{tabular}{ccccc}
\hline \multirow{2}{*}{ Pore Size } & & \multicolumn{3}{c}{ Accumulated Porosity $(\mathbf{m L} / \mathbf{g})$} \\
\cline { 3 - 5 } & & $\mathbf{1 - 1}$ & $\mathbf{1 - 2}$ & $\mathbf{2 - 1}$ \\
\hline & 1185 & $/$ & $/$ & 0.0107 \\
& 1017 & 0.0181 & 0.0181 & $/$ \\
& 182.3 & $/$ & $/$ & 0.0117 \\
\multirow{3}{*}{ Pore size $(\mathrm{nm})$} & 156.5 & 0.0191 & $/$ & $/$ \\
& 113.0 & $/$ & 0.0193 & $/$ \\
& 60.75 & $/$ & $/$ & $/$ \\
& 52.18 & 0.0205 & $/$ & $/$ \\
& 37.68 & $/$ & 0.0215 & $/$ \\
& 20.25 & $/$ & $/$ & 0.0142 \\
& 17.39 & 0.0245 & $/$ & 0.0260 \\
\hline \multicolumn{2}{c}{ Fissure volume $(\mathrm{mL} / \mathrm{g})$} & 0.0089 & 0.0089 & 0.0040 \\
\hline
\end{tabular}

Combining the moisture ratio following coal sample desorption enables the volume of fissures in each sample to be calculated (Table 5).

The water contents in pores and fissures can be calculated at different water injection pressures on the basis of fissure volumes and moisture ratios. In this context, Equation (15) can be changed into Equation (16) as

$$
V_{2}=\frac{M}{100 \rho}-V^{\prime}
$$

These results are presented in Table 6 .

Table 6. Moisture volumes in pores under different water pressures

\begin{tabular}{cccc}
\hline Desorption Condition & \multicolumn{2}{c}{ Moisture Volumes in Pores (mL/g) } \\
\cline { 2 - 4 } & $\mathbf{1 - 1}$ & $\mathbf{1 - 2}$ & $\mathbf{2 - 1}$ \\
\hline One-time water pressure for desorption & 0.0186 & 0.0185 & 0.0111 \\
Three-times water pressure for desorption & 0.0201 & 0.0194 & 0.0117 \\
Nine-times water pressure for desorption & 0.0205 & 0.0202 & 0.0130 \\
\hline
\end{tabular}

The results from $V_{2}$ and $V_{1}$ differ from one another as gas is also present in coal. Thus, based on the relationship between pore size and accumulated pore volume from our MIP experiments as well as moisture volumes in pores at different water injection pressures, critical pore sizes at different moisture ratios were calculated (Table 7).

Table 7. Moisture volumes within pores and corresponding critical pore sizes

\begin{tabular}{ccccc}
\hline \multirow{2}{*}{ Moisture Ratio } & \multicolumn{3}{c}{ Critical Pore Size (nm) } \\
\cline { 3 - 5 } & & $\mathbf{1 - 1}$ & $\mathbf{1 - 2}$ & $\mathbf{2 - 1}$ \\
\hline & 0.0128 & $/$ & $/$ & 679.6 \\
& 0.0134 & $/$ & $/$ & 182.3 \\
Moisture volumes & 0.0147 & $/$ & $/$ & 37.7 \\
in pores (mL/g) & 0.0185 & $/$ & 432.9 & $/$ \\
& 0.0186 & 349.8 & $/$ & $/$ \\
& 0.0194 & $/$ & 108.1 & $/$ \\
& 0.0201 & 66.1 & $/$ & $/$ \\
\hline
\end{tabular}




\subsection{Relationship between Desorption Capacity and Critical Pore Size}

Relationships between critical pore size and permanent desorption percentages for the three coal samples studied in this research are presented in Figure 8. These data show that for the same coal rank, desorption capacity induced by water injection is not only related to critical pore size, but also gas equilibrium adsorption pressure. In other words, at the same pore size, a higher gas pressure equates to a better desorption capacity. Desorption capacity is also related to coal rank and depends on connecting pores and the distribution law of fissures. Data show that, under the same conditions, desorption capacity increases in concert with porosity.

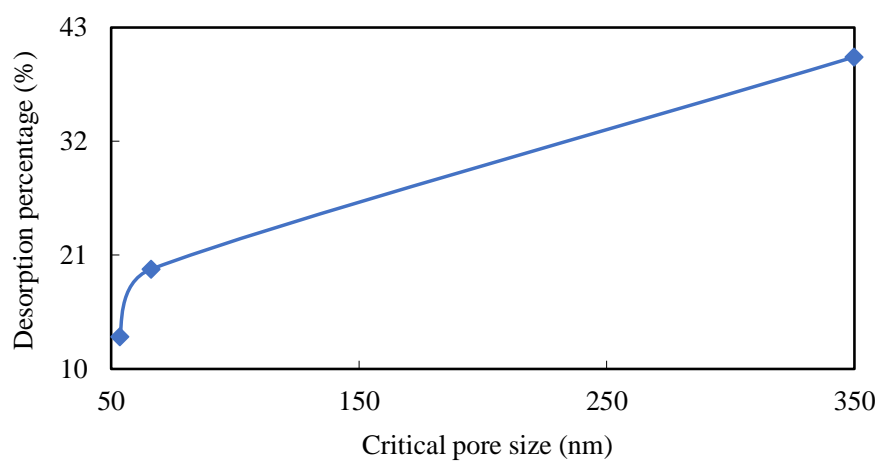

(a)

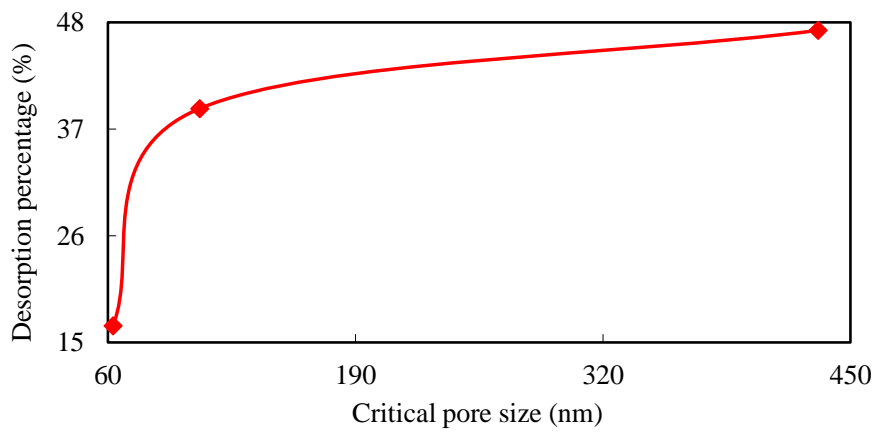

(b)

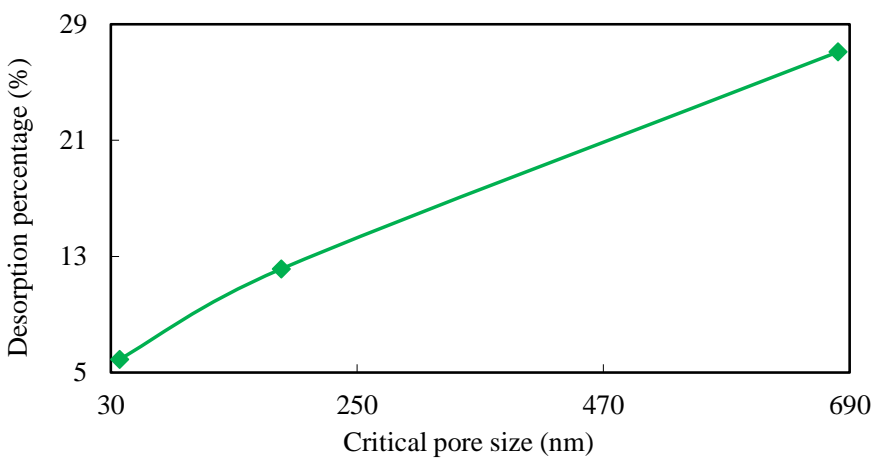

(c)

Figure 8. Critical pore size as a function of permanent desorption percentage for the three coal samples considered in this study. (a) Coal Sample 1-1; (b) Coal Sample 1-2; (c) Coal Sample 2-1.

As permanent desorption percentage is related to porosity, gas equilibrium adsorption pressure and critical pore size induced by water all exhibit positive growth over time, this relationship is summarized in Equation (17) as

$$
\eta_{T}=f\left(n, \eta_{T \max }, D\right)
$$


The monolayer adsorption theory of gas can be assessed using Equation (18) and reveals a similar relationship to the volume of water contained in pores. Equation (18) was therefore modified into Equation (19) water [40] as

$$
V_{A}=\frac{a b p}{1+b p}
$$

and

$$
\eta_{T}=\frac{\eta_{\operatorname{Tmax}} n D}{1+n D} .
$$

Thus, using Equation (19) to simulate the curves in Figure 8 leads to the results presented in Table 8. Results show that Equation (19) can accurately describe the relationship between critical pore size and desorption capacity.

Table 8. Simulated results for critical pore size

\begin{tabular}{ccc}
\hline Coal Sample & Simulation Results & Coefficient Index $\mathbf{R}^{\mathbf{2}} \mathbf{)}$ \\
\hline $1-1$ & $\eta_{T}=\frac{56.17 \times 0.0065 D}{1+0.0065 D}$ & 0.9079 \\
\hline $1-2$ & $\eta_{T}=\frac{64.48 \times 0.0066 D}{1+0.0066 D}$ & 0.7962 \\
\hline $2-1$ & $\eta_{T}=\frac{51.50 \times 0.0033 D}{1+0.0033 D}$ & 0.8828 \\
\hline
\end{tabular}

\section{Conclusions}

Two ranks of coal samples were used in this study in a series of desorption experiments at different water injection pressures combined with MIP measurements to study the relationship between desorption law and pore size distribution. This study presents a theoretical two-phase flow model, MIP, and desorption experiments to illustrate coal desorption capacity that can be induced by water injection. Our main results are as follows:

(1) A new model for critical pore size is presented here that can be used to assess theoretical water injection into coalbeds. This variable is related to water injection pressure, residual water length, and gas adsorption capacity.

(2) Variable water injection pressures lead to different gas desorption capacities and cause a range of time-related effects to influence gas desorption. Moisture ratio of residual coal samples after desorption is a few increased with water injection pressure.

(3) Critical pore size as a new parameter to illustrate desorption capacity combining with pore size distribution law has been calculated in each different experimental condition. It is increased with permanent desorption percentage.

(4) The new parameter discussed herein, critical pore size, can be used to describe the effects of high pressure water on gas desorption capacity. This variable can be calculated using pore size and relationships with volume distribution, as well as via moisture ratios subsequent to experiments and permanent desorption percentage.

Supplementary Materials: The following are available online at http:/ /www.mdpi.com/1996-1073/11/9/2345/ s1, Figure S1: Picture of abrasive wire sawing machine.

Author Contributions: Conceptualization, D.Z. and Z.F.; Methodology, D.Z.; Software, D.Z.; Validation, D.Z., and Z.F.; Formal Analysis, D.Z.; Investigation, T.G.; Resources, Z.F.; Data Curation, Y.M.; Writing-Original Draft Preparation, D.Z.; Writing-Review \& Editing, D.Z.; Visualization, D.Z.; Supervision, Z.F.; Project Administration, Z.F.; Funding Acquisition, D.Z. and Z.F.

Funding: This study was supported by the National Natural Science Foundation of China (grant nos. 51304142 and 21373146) and by the Program for Outstanding Innovation Teams of Higher Learning Institutions of Shanxi (grant year 2014). 
Acknowledgments: We sincerely thank the anonymous reviewers for improving the quality of article. We would also like to thank NSFC and Department of Education in Shanxi Province for providing funding. We thank International Science Editing (http:/ / www.internationalscienceediting.com) for language editing this manuscript.

Conflicts of Interest: The authors declare that there is no conflict of interest regarding the publication of this paper.

\section{Nomenclature}

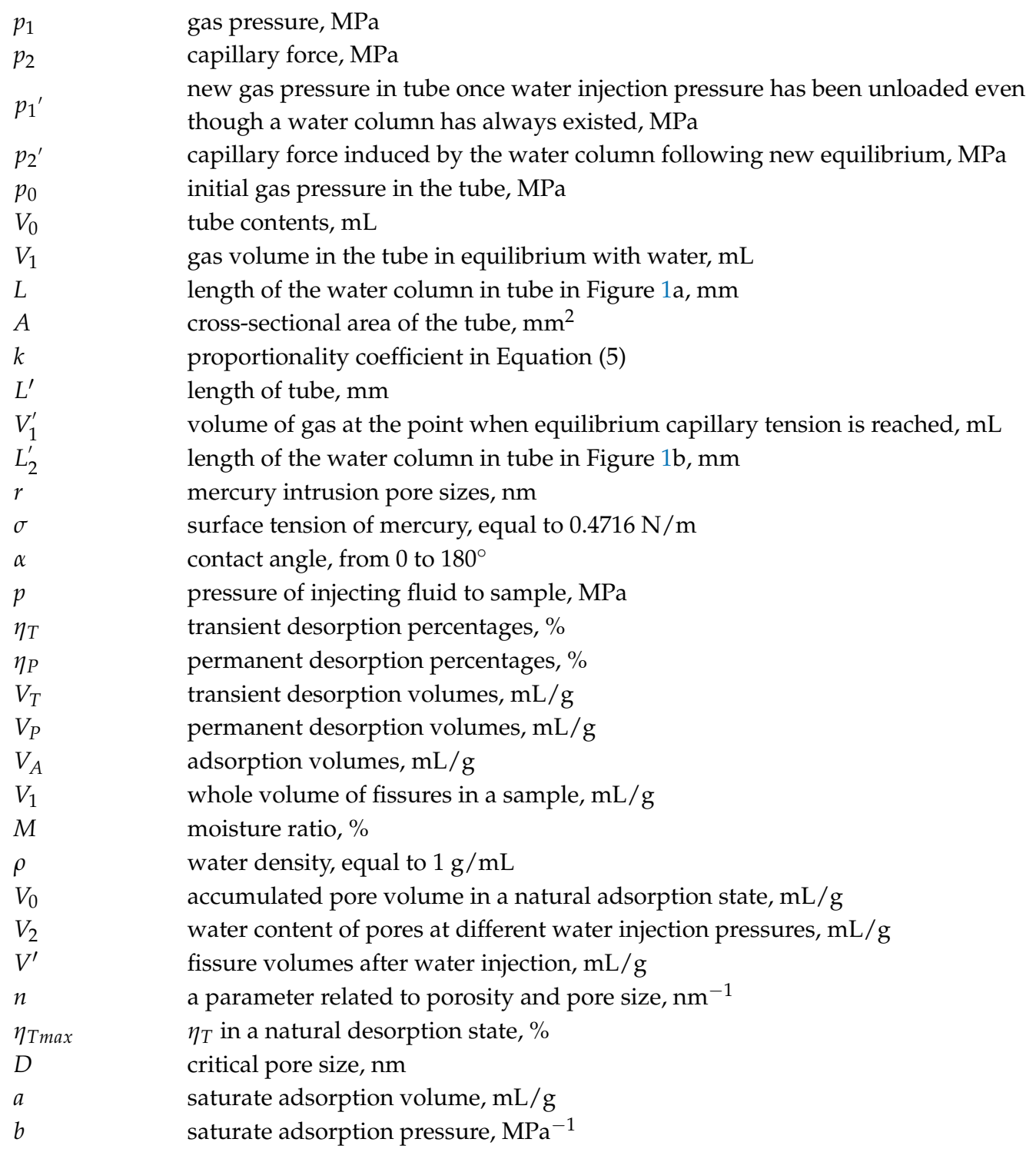

\section{References}

1. Cheung, K.; Sanei, H. Produced fluids and shallow groundwater in coalbed methane (CBM) producing regions of Alberta, Canada: Trace element and rare earth element geochemistry. Int. J. Coal Geol. 2009, 77, 338-349. [CrossRef]

2. Li, Y.; Chen, Y.F.; Zhou, C.B. Effective stress principle for partially saturated rock fractures. Rock Mech. Rock Eng. 2016, 49, 1091-1096. [CrossRef]

3. Li, Z.H.; Qi, Q.Q.; Yang, Y.L.; Zhou, Y.B.; Wang, B. Factors impacting gas content measurements using gas desorption by drilling underground boreholes. Adsorpt. Sci. Technol. 2016, 34, 488-505. [CrossRef]

4. Zhou, F.B.; Xia, T.Q.; Wang, X.X.; Zhang, Y.F.; Sun, Y.N.; Liu, J.S. Recent developments in coal mine methane extraction and utilization in China: A review. J. Nat. Gas Sci. Eng. 2016, 31, 437-458. [CrossRef]

5. Zhao, D.; Li, D.; Ma, Y.; Feng, Z.; Zhao, Y. Experimental study on methane desorption from lumpy coal under the action of hydraulic and thermal. Adv. Mater. Sci. Eng. 2018, 2018, 3648430. [CrossRef] 
6. Tang, D.Z.; Deng, C.M.; Meng, Y.J.; Li, Z.P.; Xu, H.; Tao, S.; Li, S. Characteristics and control mechanisms of coalbed permeability change in various gas production stages. Pet. Sci. 2015, 12, 684-691. [CrossRef]

7. Zhao, J.L.; Tang, D.Z.; Xu, H.; Lv, Y.M.; Tao, S. High production indexes and the key factors in coalbed methane production: A case in the Hancheng block, southeastern Ordos Basin, China. J. Pet. Sci. Eng. 2015, 130, 55-67. [CrossRef]

8. Li, H.; Lin, B.Q.; Yang, W.; Hong, Y.D.; Wang, Z. A fully coupled electromagnetic-thermal-mechanical model for coalbed methane extraction with microwave heating. J. Nat. Gas Sci. Eng. 2017, 46, 830-844. [CrossRef]

9. Zou, Q.L.; Lin, B.Q.; Liu, T.; Hu, X.C.; Zheng, C.S. Variations in coalbed gas content, initial gas desorption property and coal strength after drilling-slotting integration technique and gas drainage: Insight into pore characteristics. Int. J. Oil Gas Coal Technol. 2017, 15, 235-266. [CrossRef]

10. Chen, S.K.; Yang, T.H.; Ranjith, P.G.; Wei, C.H. Mechanism of the Two-Phase Flow Model for Water and Gas Based on Adsorption and Desorption in Fractured Coal and Rock. Rock Mech. Rock Eng. 2017, 50, 571-586. [CrossRef]

11. Beaton, A.; Langenberg, W.; Pana, C. Coalbed methane resources and reservoir characteristics from the Alberta Plains, Canada. Int. J. Coal Geol. 2006, 65, 93-113. [CrossRef]

12. Lu, T.K.; Yu, H. Improvement of methane drainage in high gassy coal seam using waterjet technique. Int. J. Coal Geol. 2009, 79, 40-48. [CrossRef]

13. Zhao, D.; Feng, Z.; Zhao, Y. Laboratory experiment on coalbed-methane desorption influenced by water injection and temperature. J. Can. Pet. Technol. 2011, 50, 24-33. [CrossRef]

14. Chen, X.J.; Chen, Y.P. Influence of the injected water on gas outburst disasters in coal mine. Nat. Hazards 2015, 76, 1093-1109. [CrossRef]

15. Wang, H.Y.; Xiao, B.W.; Lu, Y.Y.; Ge, Z.L.; Tang, J.R. Experimental study on sonic vibrating effects of cavitation water jets and its promotion effects on coalbed methane desorption. Fuel 2016, 185, 468-477. [CrossRef]

16. Yu, H.G.; Yuan, J.; Guo, W.J. A preliminary laboratory experiment on coalbed methane displacement with carbon dioxide injection. Int. J. Coal Geol. 2008, 73, 156-166. [CrossRef]

17. Li, J.; Li, X.F.; Shi, J.T.; Zhang, H.; Wu, K.L.; Chen, Z.X. Mechanism of Liquid-Phase Adsorption and Desorption in Coalbed Methane Systems: A New Insight into an Old Problem. SPE Reserv. Eval. Eng. 2017, 20, 639-653. [CrossRef]

18. Pakowski, Z.; Adamski, R.; Kokocinska, M. Generalized desorption equilibrium equation of lignite in a wide temperature and moisture content range. Fuel 2011, 90, 3330-3335. [CrossRef]

19. Liu, J.S.; Chen, Z.W.; Elsworth, D.; Miao, X.X.; Mao, X.B. Linking gas-sorption induced changes in coal permeability to directional strains through a modulus reduction ratio. Int. J. Coal Geol. 2010, 83, 21-30. [CrossRef]

20. Pan, Z.J.; Connell, L.D. Modelling of anisotropic coal swelling and its impact on permeability behaviour for primary and enhanced coalbed methane recovery. Int. J. Coal Geol. 2011, 85, 257-267. [CrossRef]

21. Wang, L.; Jiang, B. Experimental study of the effect of static water on imbibition gas recovery in coalbed methane reservoirs. J. Nat. Gas Sci. Eng. 2016, 35, 1284-1292. [CrossRef]

22. Wang, C.; Jiang, Y.J.; Liu, R.C.; Wang, C.S. Visualized Experimental Investigation on the Gas-Water Distribution Characteristics in Intersecting Fractures. Geofluids 2018, 2018, 4273450. [CrossRef]

23. Le Gal, N.; Lagneau, V.; Charmoille, A. Experimental characterization of $\mathrm{CH} 4$ release from coal at high hydrostatic pressure. Int. J. Coal Geol. 2012, 96-97, 82-92. [CrossRef]

24. Cai, Y.D.; Liu, D.M.; Pan, Z.J.; Yao, Y.B.; Li, J.Q.; Qiu, Y.K. Pore structure and its impact on CH4 adsorption capacity and flow capability of bituminous and subbituminous coals from Northeast China. Fuel 2013, 103, 258-268. [CrossRef]

25. Cheng, W.M.; Ni, G.H.; Li, Q.G.; Zheng, Y.F. Pore Connectivity of Different Ranks of Coals and Their Variations under the Coupled Effects of Water and Heat. Arab. J. Sci. Eng. 2017, 42, 3839-3847. [CrossRef]

26. Zhao, F.; Cheng, D.L. Changes in pore size distribution inside sludge under various ultrasonic conditions. Ultrason. Sonochem. 2017, 38, 390-401. [CrossRef] [PubMed]

27. Moretti, J.P.; Sales, A.; Quarcioni, V.A.; Silva, D.C.B.; Oliveira, M.C.B.; Pinto, N.S.; Ramos, L.W.S.L. Pore size distribution of mortars produced with agroindustrial waste. J. Clean. Prod. 2018, 187, 473-484. [CrossRef]

28. Zheng, S.J.; Yao, Y.B.; Liu, D.M.; Cai, Y.D.; Liu, Y. Characterizations of full-scale pore size distribution, porosity and permeability of coals: A novel methodology by nuclear magnetic resonance and fractal analysis theory. Int. J. Coal Geol. 2018, 196, 148-158. [CrossRef] 
29. Zhao, Y.X.; Sun, Y.F.; Liu, S.M.; Wang, K.; Jiang, Y.D. Pore structure characterization of coal by NMR cytophotometry. Fuel 2017, 190, 359-369. [CrossRef]

30. Liu, X.L.; Wu, C.F. Simulation of dynamic changes of methane state based on NMR during coalbed methane output. Fuel 2017, 194, 188-194. [CrossRef]

31. Ma, T.; Rutqvist, J.; Oldenburg, C.M.; Liu, W.Q.; Chen, J.G. Fully coupled two-phase flow and poromechanics modeling of coalbed methane recovery: Impact of geomechanics on production rate. J. Nat. Gas Sci. Eng. 2017, 45, 474-486. [CrossRef]

32. Liu, P.; Qin, Y.P.; Liu, S.M.; Hao, Y.J. Non-linear gas desorption and transport behavior in coal matrix: Experiments and numerical modeling. Fuel 2018, 214, 1-13. [CrossRef]

33. Sun, Z.; Shi, J.T.; Zhang, T.; Wu, K.L.; Feng, D.; Sun, F.R.; Huang, L.; Hou, C.H.; Li, X.F. A fully-coupled semi-analytical model for effective gas/water phase permeability during coal-bed methane production. Fuel 2018, 223, 44-52. [CrossRef]

34. Zou, M.J.; Wei, C.T.; Zhang, M.; Lv, X.C. Quantification of Gas and Water Transfer between Coal Matrix and Cleat Network during Drainage Process. J. Energy Resour. Technol. Trans. ASME 2018, 140, 032905. [CrossRef]

35. Xue, S.; Wang, Y.C.; Xie, J. A coupled approach to simulate initiation of outbursts of coal and gas-Model development. Int. J. Coal Geol. 2011, 86, 222-230. [CrossRef]

36. Thararoop, P.; Karpyn, Z.T.; Ertekin, T. Numerical studies on the effects of water presence in the coal matrix and coal shrinkage and swelling phenomena on $\mathrm{CO}_{2}$-enhanced coalbed methane recovery process. Int. J. Oil Gas Coal Technol. 2012, 5, 47-65. [CrossRef]

37. Nie, B.S.; Zhang, L.; Ma, W.F. Diffusion micro-mechanism of coal bed methane in coal pores. Coal Geol. Explor. 2000, 28, 20-22. (In Chinese)

38. Wang, H.M. Mercury determination the error of structure of porous materials. Guangzhou Chem. Ind. 2009, 37, 109-111. (In Chinese)

39. Cai, T.T.; Feng, Z.C.; Zhou, D. Multi-scale characteristics of coal structure by x-ray computed tomography (X-ray $\mathrm{CT}$ ), scanning electron microscope (SEM) and mercury intrusion porosimetry (MIP). AIP Adv. 2018, 8, 025324. [CrossRef]

40. Langmuir, I. The constitution and fundamental properties of solids and liquids. J. Am. Chem. Soc. 1916, 38, 2221-2295. [CrossRef] 